\title{
Development of Health Indices and Market Segmentation Strategies for Senior Health Services*
}

\author{
Jeong-Hun Shin** \\ Received: October 10, 2018. Revised: October 30, 2018. Accepted: November 10, 2018.
}

\begin{abstract}
Purpose - This study surveys factors such as lifestyles, nutritional status, physical indicators, and physical fitness levels that affect the health of seniors over the age of 65 and based on the collected data attempts to create a senior health index model that provides health service information, help support seniors' successful aging, and improve their quality of life.

Research design, data, and methodology - This paper conducted the development for senior health index model and the cross validity verification to examine the status of senior health level, and aimed at setting the health status evaluation criteria. Seniors 384 usable data were analyzed.

Results - As an attempt to segment the senior health service market, I divided the results of this study based on measurability, accessibility, disparity between groups, and the size of the potential client base. I divided the senior market into five subgroups: very healthy, healthy, normal, weak, and very weak.

Conclusions - The findings of this study may prove useful in preparing for the forthcoming super-aged society through segmentation of the senior market, understanding differences between groups with different health conditions, and discovering effective marketing strategies that meet the demands of different senior groups.
\end{abstract}

Keywords: Senior Health Index, Market Segmentation, Personalized Marketing.

JEL Classifications: I11, I31.

\section{Introduction}

The average life span of seniors became longer as the standard of life has been improved, and medical technology has developed in Korea. While the population of seniors is increasing along with the trend of the low birth rate. The UN is classified as an aging society when the age 65 or more takes $7 \%$ of the total population, as an aged society when it takes over $14 \%$, and as a super-aged society when it takes over $20 \%$. According to statistics Korea (2015), the number of seniors has already taken $18.5 \%$ of JeonNam province's total population, which means an aged society, expecially Naju City, Hampyeong-Gun, Jangseong-Gun, Hwasun-Gun have already categorized in the super aged

* This study was supported by research fund from Songwon University 2018.

** First Author, Dept. of Social Physical Education, Songwon Univ., Gwang-Ju, Korea.

Tel: +82-62-360-5947, E-mail: shin1014@hanmail.net society in 2005. The main interest of this super aged society will be how to live long in health(Lee \& Kim, 2011), but in reality, the medical cost for the seniors are reached Won 22,000,000 million each year, so the importance of the seniors' health care is increasing to prevent economic burden, too(Shin \& Ji, 2017). Physical activities of the seniors have a great impact on their life, such as prevention of various diseases, fitness improvement, satisfaction of life, sound leisure activities, and health maintenance, etc. and they are essential for keeping in health(Lee, 2016; Lee \& Kim, 2011).

Factors influencing the health of seniors are smoking, eating habits, exercising habits, lifestyle related to stress (Kim, 2015), or physical activities and ranges of behavior (Koo \& Park, 2011). The health condition of seniors also contributes to the reduction of the national health cost and improvement of quality of life. In addition, many scholars keep studying on successful aging of seniors(Park, Ko, Song, Song, Chung, Park, \& Lee, 2016; Chang, 2015; Ghassemzadeh, 2013; Lee, Kim, \& Chang, 2008), and 
interest in the quality of life and successful aging are increasing more and more(Jung, 2017).

However, physical aging of seniors has an impact on their own life, such as increased death rate and poor quality of life, leading to an increase in the seniors' disease incidences and their medical costs(Bang \& Jang, 2007). Physical aging is difficult to evaluate due to individual differences such as genetic factors, physical activity level, nutrition and health conditions. Therefore, researchers suggest that many variables related to aging should be analyzed and evaluated by the same index like the age scale(Clark, 1960; Jung, Kim, Kim, Choi, Park, Tanaka, Jung, \& Nho, 2017).

However, since measurable standards for senior health services haven't yet been established and accordingly current health assessment methods are unreliable, market segmentation would be a difficult task.

There are four essential elements that are required for successful market segmentation: measurability which allows for distribution of useful personalized information that satisfy different demands, accessibility which ensures the delivery of products and services, conceptual disparity between different markets and groups, and a large enough potential client base. In short, individuals have varying demands and health conditions, but can share similar lifestyles, nutritional status, physical indicators, and physical fitness. Dividing the market into groups based on these similarities would prove extremely useful.

The purpose of the study is to examine the life style, nutritional status, physical indicators, and fitness level that affect seniors aged 65 years and over for their healthy lives. On the basis of the related facts, this paper designs seniors' health index model that can evaluate the level of their health condition, and set up an health evaluation standard with cross validity verification. Therefore, the health evaluation standard provide seniors with helpful information for their successful aging and improved quality of life.

Based on these findings, I will offer strategies to respond to the imminent super-aged society through market segmentation and deliver personalized health services to seniors.

\section{Research Methodology}

\subsection{Participants}

The purpose of this study is to segment the senior market based on factors such as lifestyle, nutritional status, physical indicators, and physical fitness and in doing so create new marketing strategies.

The participants are members in a senior center and a welfare facility for seniors in G Metropolitan City. The researcher explained the purpose and method of this study, and got concent from them. The participants are divided into the health group and the health risk group. A total of 384 subjects are included in this study, 314 subjects in the health group, mean age $72.51 \pm 2.03$ years and BMI $23.59 \pm 3.24 \mathrm{~kg} / \mathrm{m}^{2}$. and 70 subjects in the health rish group, mean age $73.03 \pm 1.98$ years, BMl $25.92 \pm 3.17 \mathrm{~kg} / \mathrm{m}^{2}$. The physical characteristics of the subjects are presented in $<$ Table $1>$.

\subsection{Research Ethics Approval}

This research is conducted with the approval of the IRB designated by the Ministry of Health and Welfare after submitting research proposals, consensus and research journals.

\subsection{Selection and Distribution of Participants}

To select the participants of this study, in life habit as a subject area, three or more of the five items belongs to normal level is categorized as the health group. In nutritional habit score distribution, the normal range is classified as the health group, and out of normal range is classified as the health risk group. Followings are object measurement standards, blood pressure high 100-140, blood pressure low $60-100$, stable heart rate $60-80$ times $/ \mathrm{min}$, BMI $20-27 \mathrm{~kg} / \mathrm{m}^{2}$, three out of total 4 items is in normal range, it is classified as the health group and out of this range is categorized as

Table 1: Baseline characteristics of the study participants

\begin{tabular}{|c|c|c|c|c|c|c|c|c|c|c|}
\hline \multirow[t]{2}{*}{ Group } & \multirow[t]{2}{*}{ Age } & \multirow[t]{2}{*}{ No. } & \multicolumn{2}{|c|}{$\begin{array}{c}\text { Age } \\
\text { (year) }\end{array}$} & \multicolumn{2}{|c|}{$\begin{array}{l}\text { Height } \\
(\mathrm{cm})\end{array}$} & \multicolumn{2}{|c|}{$\begin{array}{l}\text { Weight } \\
(\mathrm{kg})\end{array}$} & \multicolumn{2}{|c|}{$\begin{array}{c}\text { BMl } \\
\left(\mathrm{kg} / \mathrm{m}^{2}\right)\end{array}$} \\
\hline & & & $\bar{x}$ & SD & $\bar{x}$ & SD & $\bar{x}$ & SD & $\bar{x}$ & $\mathrm{SD}$ \\
\hline \multirow{4}{*}{$\begin{array}{l}\text { Healthy } \\
\text { Group }\end{array}$} & $65-70$ years old & 164 & 66.20 & 1.68 & 158.83 & 8.56 & 59.04 & 9.59 & 23.45 & 3.74 \\
\hline & $71-75$ years old & 86 & 73.00 & 1.56 & 159.15 & 8.91 & 60.24 & 9.94 & 23.77 & 3.30 \\
\hline & 76 years and older & 64 & 78.34 & 2.84 & 159.89 & 8.23 & 60.28 & 8.52 & 23.56 & 2.68 \\
\hline & Average & 314 & 72.51 & 2.03 & 159.29 & 8.57 & 59.85 & 9.35 & 23.59 & 3.24 \\
\hline \multirow{4}{*}{$\begin{array}{l}\text { Healthy } \\
\text { Risk } \\
\text { Group }\end{array}$} & $65-70$ years old & 28 & 66.50 & 1.75 & 154.95 & 5.54 & 67.07 & 11.33 & 28.00 & 4.83 \\
\hline & $71-75$ years old & 24 & 73.58 & 1.35 & 156.88 & 5.41 & 59.05 & 7.58 & 23.93 & 1.99 \\
\hline & 76 years and older & 18 & 79.00 & 2.83 & 156.49 & 6.66 & 63.31 & 7.92 & 25.83 & 2.68 \\
\hline & Average & 70 & 73.03 & 1.98 & 156.11 & 5.87 & 63.14 & 8.94 & 25.92 & 3.17 \\
\hline
\end{tabular}


the health risk group. In the seven items for seniors' physical fitness measurement, the health group is classified when more than four items belongs to normal level, but less than four is classified as the health risk group. the sample size is calculated by using 384 people participated in this research to validate the health index by age.

\subsection{Measurement Items \& Method}

This study established check lists and conducted measurement both for subjective and for objective areas to calculate the health index closely related to seniors' health condition. For data analysis, a questionnaire for their life style and nutrition status as a subjective evaluation area, and body index and seniors' fitness test as an objective evaluation area are included.

\subsubsection{Lifestyle Questionnaire}

The lifestyle questionnaire is Healthy Lifestyle Quiz(U.S. Department of Health and Human Service, 1981), which is translated in Korean by Shin(2015) and Ahn and Shin(2008). The questionnaire shows a high validity of .627-.901 and a high reliability of .8005-.9040. The sub-factors are smoking, drinking and medication, diet, exercise, and stress control. The subjects self reported it. Lifestyle questionnaires are rated $0-10$ points for each sub-factor. According to the score, above 9 point is rated Excellent(EG), 6-8 points are Health Good(HG), 3-5 points are Health Risk(HR) and below 2 points is Health High Risk(HHR). The higher the score, the more positive the lifestyle is.

\subsubsection{Nutrition Status Questionnaire}

Nutritional status questionnaires are a guidebook of the Korean Nutrition Survey developed by the Ministry of Health and Welfare(2013) and Nutritional Assessment by Guigoz, Vellas, and Garry (1994). Followings are criteria for classification. A score below 17 points for malnutrition, 17 points to 23.5 points for malnutrition, and a score above 24 points for normal. The higher the score, the better the nutritional status is.

\subsubsection{Physical Indicator Measurement}

Physical indicators are measured by using a digital blood pressure monitor(BMI), blood pressure measurement, and resting heart rate measurement. The researchers and research assistants directly measured the subjects to minimize errors.

\subsubsection{Senior's Fitness Measurement}

Seniors' physical fitness test is carried out by using the Senior Fitness Test Manual(Jones, 2013) based on the following data: lower body strength(sitting up from the chair), lower limb flexibility(sitting on the chair), agility and dynamic balance( $2.4 \mathrm{~m}$ round trip)(Kim, Jeong, \& Park, 2014). However, 6-minute walking(whole-body endurance) measurement is excluded considering the seniors' time and physical burden.

\subsection{Segmentation process and Data Analysis}

In this study, the segmentation process is differentiated by demographic characteristics according to the subdivision market, so it is necessary to establish a differentiated marketing strategy for each subdivision market (Yu \& Yoon, 2011). The importance of segmentation for the elderly marketing is increasing, but systematic classification is insufficient. In this study, we proposed a homogeneity analysis method to evaluate the appropriateness of subdivision classification like Bae (2010) study for systematic subdivision classification method based on characteristics of elderly person.

There are four essential elements that are required for successful market segmentation: measurability which allows for distribution of useful personalized information that satisfy different demands, accessibility which ensures the delivery of products and services, conceptual disparity between different markets and groups, and a large enough potential client base. In short, individuals have varying demands and health conditions, but can share similar lifestyles, nutritional status, physical indicators, and physical fitness. Dividing the market into groups based on these similarities would prove extremely useful.

We conducted segmentation classification for the marketing of the study subjects and verified the homogeneity according to the physical characteristics to measure how the classified subdivision coincides with the physical characteristics of the elderly.

For data analysis, the mean and variance are measured, according to the physical characteristics of the seniors. And to verify changes between age and group, pre measured value is set as a covariance, and then analysis of covariance is conducted. Next, to investigate the difference between the main effects, post-test is performed using Scheffe. In addition, correlation analysis and regression analysis (simultaneous input method) are conducted to analyze the variables affecting the health by the measurement items. In order to verify the cross validation of the health index calculation model, the subjects are divided into the health group and the health risk group. And cross-validation and the independent sample t-test are conducted to compare actual age and the health indices between age groups. The statistical significance level is set to $\alpha=.05$

\section{Results}

\subsection{Comparison of Age-Specific Measurement Items}

As shown in $\langle$ Table 2>, in the comparison of the group-by-age items, lifestyle habits in stress control are $6.60 \pm 1.78$ in the $71-75$ age group, $6.97 \pm 1.46$ in the above 
76 age group of the health group. While $6.97 \pm 1.73$ in $65-70$ age group of the health risk group $(p<.001)$, and the main effect test shows a significant difference between 65-70 years old and over 76 years old.

For physical index comparison, the mean blood pressure high ranged from $130.40 \pm 14.67 \mathrm{mmHg}$ in $65-70$ age group, $133.79 \pm 17.71 \mathrm{mmHg}$ in $71-75$ age group, and $138.38 \pm 20.75 \mathrm{~mm}$ $\mathrm{Hg}$ in above 76 age group. So the health group shows normal blood pressure range at all age groups. $(p<.01)$. The main effect test shows a significant difference between the ages of $65-70$ and above 76 years old. The blood pressure low is $75.12 \pm 8.98 \mathrm{mmHg}$ at $65-70$ years, $78.35 \pm 6.94 \mathrm{mmHg}$ at 71-75 years, $80.16 \pm 8.94 \mathrm{mmHg}$ at 76 years or older. So normal blood pressure is found at all ages in the health group $(p<.001)$. As a result of the main effect test, there is a significant difference between the ages of 65-70, 71-75, and above 76 . The heart rate is $70.70 \pm 1.38 / \mathrm{min}$ at the age of $65-70,70.56 \pm 4.31 / \mathrm{min}$ at the age of $71-75$, and $73.22 \pm 6.67 / \mathrm{min}$ at the age of 76 and above. Stable heart rate is found in all age groups $(p<.001)$. The result shows that there is a significant difference between the ages of 65-70, 71-75 and above 76 years old.

The seniors in the health group show high fitness level of low body strength in all age group $(p<.001)$. The results are $21.60 \pm 4.94$ set in $65-70$ age group, $19.42 \pm 5.14$ set in $71-75$ age group, $16.03 \pm 3.12$ set in above 75 age group. There was a significant difference between ages of 65-70, 71-75 and above 76 years old. Agility and dynamic equilibrium are $6.81 \pm 1.11 \mathrm{sec}$ for $65-70$ years, $7.52 \pm 1.41 \mathrm{sec}$ for $71-75$ years, $7.64 \pm 1.06 \mathrm{sec}$ for above 76 years $(p<.001)$. There is a significant difference of the main effect test among 65-70 years old, 71-75 years old, above 76 years old, and between 71-75 years old and above 76 years old.

In addition, upper body strength is $38.77 \pm 5.88$ set in $65-70$ age group, $34.44 \pm 9.75$ set at $71-75$ age group, and $29.75 \pm 11.07$ set at 76 years old and over, showing a high level of fitness at all age groups in the health group( $p$ $<.001)$. There are significant differences among the ages of 65-70, 71-75 and above 76, and between 71-75 and above 76 .

In the health group, the upper body flexibility is $-3.57 \pm 20.02 \mathrm{~cm}$ in the $71-75$ age group, and in the health risk group, it is $-0.4 \pm 6.19 \mathrm{~cm}$ in the $65-70$ age group, and $-3.27 \pm 7.47 \mathrm{~cm}$ in the above 75 age group which shows good fitness level $(p<.05)$. And the main effect test shows a significant difference between $65-70$ age group and over 76 age group.

Table 2: Comparison of Healthy measurements in groups by age

\begin{tabular}{|c|c|c|c|c|c|c|c|c|c|}
\hline \multirow{2}{*}{\multicolumn{2}{|c|}{$\begin{array}{l}\text { Measurement Items } \\
\text { (unit) }\end{array}$}} & \multirow[t]{2}{*}{ Group } & \multicolumn{2}{|c|}{$65-70$ years old (a) } & \multicolumn{2}{|c|}{$71-75$ years old (b) } & \multicolumn{2}{|c|}{$\begin{array}{l}76 \text { years old and } \\
\text { older (c) }\end{array}$} & \multirow{2}{*}{$\begin{array}{l}\text { Age } \times \text { Group } \\
\text { F / Post-hoc }\end{array}$} \\
\hline & & & $\mathbf{M}$ & SD & M & SD & $\mathbf{M}$ & SD & \\
\hline \multirow{10}{*}{$\begin{array}{l}\text { Life } \\
\text { Style }\end{array}$} & \multirow{2}{*}{ Smoking } & Healthy Group & 6.96 & 4.06 & 8.65 & 3.12 & 7.78 & 3.60 & \multirow{2}{*}{2.026} \\
\hline & & Healthy Risk Group & 9.29 & 2.62 & 8.67 & 3.16 & 7.33 & 4.00 & \\
\hline & \multirow{2}{*}{ Alcohol and Drug } & Healthy Group & 6.49 & 2.79 & 6.72 & 3.05 & 7.00 & 2.52 & \multirow{2}{*}{.505} \\
\hline & & Risk Group & 4.86 & 3.31 & 7.58 & 2.69 & 7.11 & 2.63 & \\
\hline & \multirow{2}{*}{$\begin{array}{c}\text { Dietary Life } \\
\text { (point) }\end{array}$} & Healthy Group & 5.50 & 2.78 & 6.47 & 2.36 & 6.00 & 2.70 & \multirow{2}{*}{1.622} \\
\hline & & Healthy Risk Group & 6.00 & 2.91 & 5.58 & 3.08 & 5.67 & 2.61 & \\
\hline & \multirow{2}{*}{$\begin{array}{c}\text { Exercise } \\
\text { (point) }\end{array}$} & Healthy Group & 5.77 & 2.24 & 6.33 & 2.29 & 6.38 & 2.13 & \multirow{2}{*}{1.281} \\
\hline & & Healthy Risk Group & 6.07 & 2.92 & 4.75 & 2.51 & 5.78 & 2.05 & \\
\hline & \multirow{2}{*}{$\begin{array}{l}\text { Stress Control } \\
\text { (point) }\end{array}$} & Healthy Group & 6.29 & 1.55 & 6.60 & 1.78 & 6.97 & 1.46 & \multirow{2}{*}{$\begin{array}{c}7.053^{\star * *} \\
\text { (a)-(c) }\end{array}$} \\
\hline & & Healthy Risk Group & 6.79 & 1.73 & 6.00 & 1.18 & 6.56 & 1.54 & \\
\hline \multirow{2}{*}{\multicolumn{2}{|c|}{$\begin{array}{l}\text { Nutritive Conditions } \\
\text { (point) }\end{array}$}} & Healthy Group & 25.87 & 2.37 & 25.38 & 2.45 & 25.50 & 3.26 & \multirow{2}{*}{.194} \\
\hline & & Healthy Risk Group & 24.68 & 2.38 & 23.71 & 2.55 & 26.22 & 2.95 & \\
\hline \multirow{8}{*}{$\begin{array}{l}\text { Physical } \\
\text { Index }\end{array}$} & \multirow{2}{*}{$\begin{array}{c}\text { B.M.I } \\
\left(\mathrm{kg} / \mathrm{m}^{2}\right)\end{array}$} & Healthy Group & 23.45 & 3.74 & 23.77 & 3.30 & 23.56 & 2.68 & \multirow{2}{*}{.960} \\
\hline & & Healthy Risk Group & 28.00 & 4.83 & 23.93 & 1.99 & 25.83 & 2.68 & \\
\hline & \multirow{2}{*}{$\begin{array}{l}\text { Blood Pressure-high } \\
(\mathrm{mmHg})\end{array}$} & Healthy Group & 130.40 & 14.67 & 133.79 & 17.71 & 138.38 & 20.75 & \multirow{2}{*}{$\begin{array}{l}6.246^{* *} \\
\text { (a)-(c) }\end{array}$} \\
\hline & & Healthy Risk Group & 151.36 & 10.52 & 156.08 & 8.40 & 155.78 & 8.76 & \\
\hline & \multirow{2}{*}{$\begin{array}{l}\text { Blood Pressure-low } \\
\quad(\mathrm{mmHg})\end{array}$} & Healthy Group & 75.12 & 8.98 & 78.35 & 6.94 & 80.16 & 8.94 & \multirow{2}{*}{$\begin{array}{l}8.265^{\star * *} \\
\text { (a)-(b), (c) }\end{array}$} \\
\hline & & Healthy Risk Group & 86.36 & 13.07 & 96.83 & 10.69 & 83.44 & 10.60 & \\
\hline & \multirow{2}{*}{$\begin{array}{l}\text { Resting Heart Rate } \\
\text { (No./Min.) }\end{array}$} & Healthy Group & 70.70 & 1.38 & 70.56 & 4.31 & 73.22 & 6.67 & \multirow{2}{*}{$\begin{array}{l}5.467^{* *} \\
\text { (a),(b)-(c) }\end{array}$} \\
\hline & & Healthy Risk Group & 75.71 & 9.34 & 79.67 & 6.79 & 69.33 & 16.13 & \\
\hline \multirow{6}{*}{$\begin{array}{l}\text { Elderly } \\
\text { Fitness }\end{array}$} & \multirow{2}{*}{$\begin{array}{l}\text { Lower body strength } \\
\text { (set) }\end{array}$} & Healthy Group & 21.60 & 4.94 & 19.42 & 5.14 & 16.03 & 3.12 & $22.398^{\star \star *}$ \\
\hline & & Healthy Risk Group & 17.36 & 4.75 & 16.42 & 4.98 & 13.67 & 4.17 & (a),(b)-c) \\
\hline & Lower body flexibility & Healthy Group & 12.98 & 9.49 & 12.78 & 7.36 & 9.73 & 8.94 & \\
\hline & $(\mathrm{cm})$ & Healthy Risk Group & 11.80 & 12.29 & 15.17 & 8.71 & 6.18 & 5.60 & 1.4 \\
\hline & Agility \& balance & Healthy Group & 6.81 & 1.11 & 7.52 & 1.41 & 7.64 & 1.06 & $11.687^{* * *}$ \\
\hline & $(\mathrm{sec})$ & Healthy Risk Group & 7.79 & 1.89 & 7.56 & 1.34 & 8.57 & 1.44 & (a)-(b), (c)/(b)-(c) \\
\hline
\end{tabular}




\begin{tabular}{|c|c|c|c|c|c|c|c|c|c|}
\hline \multirow{6}{*}{$\begin{array}{l}\text { Elderly } \\
\text { Fitness }\end{array}$} & \multirow{2}{*}{$\begin{array}{l}\text { Upper body strength } \\
\text { (set) }\end{array}$} & Healthy Group & 38.77 & 5.88 & 34.44 & 9.75 & 29.75 & 11.07 & \multirow{2}{*}{$\begin{array}{c}27.492^{\star * *} \\
\text { (a)-(b),(c)/(b)-(c) }\end{array}$} \\
\hline & & Healthy Risk Group & 30.64 & 9.50 & 22.58 & 7.44 & 21.89 & 8.45 & \\
\hline & \multirow{2}{*}{$\begin{array}{l}\text { Upper body flexibility } \\
(\mathrm{cm})\end{array}$} & Healthy Group & -.53 & 4.97 & -3.57 & 20.02 & -7.78 & 25.90 & \multirow{2}{*}{$\begin{array}{r}3.773^{*} \\
\text { (a)-(c) }\end{array}$} \\
\hline & & Healthy Risk Group & -.04 & 6.19 & -5.28 & 7.73 & -3.27 & 7.47 & \\
\hline & \multirow{2}{*}{$\begin{array}{c}\text { Total body endurance } \\
\text { (set) }\end{array}$} & Healthy Group & 93.66 & 12.02 & 89.61 & 88.93 & 82.11 & 24.54 & \multirow{2}{*}{.905} \\
\hline & & Healthy Risk Group & 70.15 & 22.77 & 90.96 & 19.14 & 72.34 & 23.62 & \\
\hline
\end{tabular}

${ }^{*} p<.05,{ }^{* *} p<.01,{ }^{* * *} p<.001$

Table 3: Correlation analysis on senior health index

\begin{tabular}{|c|c|c|c|c|c|c|c|c|c|c|c|c|c|c|c|c|c|}
\hline & $\mathrm{X} 1$ & $\mathrm{X} 2$ & $\mathrm{X} 3$ & $\mathrm{X} 4$ & $\times 5$ & $\mathrm{X} 6$ & $\mathrm{X} 7$ & $\mathrm{X} 8$ & $\times 9$ & $\mathrm{X} 10$ & $\mathrm{X} 11$ & $\mathrm{X} 12$ & X13 & $\mathrm{X} 14$ & $\mathrm{X} 15$ & X16 & $\mathrm{X} 17$ \\
\hline $\mathrm{X} 1$ & 1 & & & & & & & & & & & & & & & & \\
\hline $\mathrm{X} 2$ & .033 & 1 & & & & & & & & & & & & & & & \\
\hline $\mathrm{X} 3$ & $.176^{\star *}$ & $-.141^{*}$ & 1 & & & & & & & & & & & & & & \\
\hline $\mathrm{X} 4$ & $.182^{\star \star}$ & $.123^{*}$ & .090 & 1 & & & & & & & & & & & & & \\
\hline $\mathrm{X} 5$ & $.192^{\star \star}$ & $.173^{\star \star}$ & .020 & $.551^{\star \star}$ & 1 & & & & & & & & & & & & \\
\hline $\mathrm{X} 6$ & $-.368^{* *}$ & $-.152^{* *}$ & \begin{tabular}{|l|}
-.041 \\
\end{tabular} & $-.126^{*}$ & $-.146^{* *}$ & 1 & & & & & & & & & & & \\
\hline $\mathrm{X} 7$ & $-.130^{*}$ & $.180^{* *}$ & $-.215^{\star \star}$ & -.012 & $.116^{*}$ & $.310^{\star *}$ & 1 & & & & & & & & & & \\
\hline $\mathrm{X} 8$ & $.323^{\star \star}$ & .094 & .092 & .074 & .103 & $-.532^{\star \star}$ & $-.193^{\star *}$ & 1 & & & & & & & & & \\
\hline $\mathrm{X9}$ & $-.406^{\star \star}$ & $-.111^{*}$ & $-.141^{*}$ & $-.180^{* *}$ & $-.235^{\star *}$ & $.454^{\star *}$ & .090 & $-.377^{\star \star}$ & 1 & & & & & & & & \\
\hline $\mathrm{X} 10$ & $-.161^{* *}$ & -.089 & $-.305^{\star \star}$ & -.025 & $-.141^{*}$ & $.127^{*}$ & .002 & $-.247^{\star *}$ & $.301^{* *}$ & 1 & & & & & & & \\
\hline $\mathrm{X} 11$ & -.092 & $.149^{\star \star}$ & -.032 & .043 & $.111^{*}$ & $-.142^{*}$ & -.098 & .060 & .087 & .053 & 1 & & & & & & \\
\hline $\mathrm{X} 12$ & .086 & .089 & $.188^{\star \star}$ & $.251^{* *}$ & $.410^{\star \star}$ & -.030 & .064 & $.211^{* *}$ & $-.211^{\star *}$ & $-.142^{*}$ & .001 & 1 & & & & & \\
\hline $\mathrm{X} 13$ & .005 & $210^{* *}$ & .103 & $.114^{*}$ & $.225^{* *}$ & -.108 & $.174^{\star *}$ & $.226^{\star *}$ & -.087 & $-.126^{*}$ & $.134^{*}$ & $.348^{* *}$ & 1 & & & & \\
\hline $\mathrm{X} 14$ & $.160^{\star \star}$ & $.206^{\star *}$ & .048 & .055 & .089 & -.018 & .086 & $.173^{\star *}$ & $-.167^{\star *}$ & .015 & -.010 & $.309^{* *}$ & $.310^{\star *}$ & 1 & & & \\
\hline $\mathrm{X} 15$ & $.119^{*}$ & .058 & $.179^{\star \star}$ & $.236^{\star \star}$ & $.209^{* *}$ & -.066 & .062 & $.130^{*}$ & -.011 & .009 & -.067 & $.236^{\star *}$ & $.232^{\star \star}$ & $.424^{\star \star}$ & 1 & & \\
\hline $\mathrm{X} 16$ & $.194^{* *}$ & .076 & .055 & -.025 & .022 & -.093 & -.042 & .088 & -.105 & -.064 & -.092 & .054 & -.004 & $.233^{* \star}$ & $.371^{* *}$ & 1 & \\
\hline $\mathrm{X} 17$ & -.024 & $237^{* *}$ & $-.189^{\star *}$ & .010 & -.052 & .051 & $.149^{\star *}$ & $-.151^{\star *}$ & $.247^{\star *}$ & $.301^{* *}$ & -.034 & $-.172^{\star *}$ & -.056 & -.002 & .059 & $.286^{* *}$ & 1 \\
\hline
\end{tabular}

* $p<.05$ ** $p<.01 \quad X 1=A g e, X 2=B M I, X 3=H e a r t$ rate, X4=Blood pressure-high, X5=Blood pressure-low, X6=Lower body strength, $X 7=$ Lower body flexibility, X8=Agility \& balance, X9=Upper body strength, $X 10=$ Upper body flexibility, X11=Total body endurance, $\mathrm{X} 12=$ Smoking, $\mathrm{X} 13=\mathrm{Alcohol}$ and drug, X14=Nutritive conditions, $\mathrm{X} 15=$ Exercise, $\mathrm{X} 16=$ Stress control, $\mathrm{X} 17=$ Total nutrition

\subsection{Health Index Measurement}

\subsubsection{Correlation Analysis for Health Index Approximate Calculation}

As shown in $\langle$ Table 3$\rangle$, in the correlation analysis for seniors' health index calculation method, seniors' age is calculated from the BMl of the physical index,

There is a significant correlation with all items except the whole body endurance of seniors fitness, smoking habits, drinking and medication, and generall nutrition in daily life. BMl of physical index shows a significant correlation with all measurement items except upper body flexibility, smoking, exercise, and stress control. Seniors' physical strength is significantly correlated with the factors of the lifestyle habits and the sub-factors of the physical indicators. The general nutritional of the seniors is significantly correlated with the measurements items except blood pressure high, blood pressure low, lower body strength, whole body endurance deformation, drinking and medication, diets and exercising hatibs.

\subsubsection{Health index approximate calculation through} Regression Analysis

As shown in $\langle$ Table $4>$, to set senior's health index approximate calculation, the present age is set as a reference variable among the 17 measured items. In order to estimate the regression model, I used Stepwise method to optimize it depending on the significance of the independent variables step by step. The multiple regression coefficient is $R=.520$, and $R^{2}$, the explanatory power of the regression coefficient, is .624 , which explains $62.4 \%$. The verification $F$ value of variance analysis model is 16.188 and statistically significant at $p<.001$ level. The variables affecting the health index predictors of the seniors are upper body strength $(\beta=-.129)$, lower body strength $(\beta=-.188)$, stress control $(\beta=1.024)$, stable heart $\operatorname{rate}(\beta=140)$, blood pressure high $(\beta$ $=.035)$, agility and dynamic equilibrium $(\beta=.506)$, and total body endurance deformation $(\beta=-.003)$. These are affecting seniors' health indicators $\langle$ Table $4>$.

New health indicators $=58.271-.129 \times \mathrm{X} 1-.188 \times \mathrm{X} 2+$ $1.024 \times \mathrm{X} 3+.140 \times \mathrm{X} 4+.035 \times \mathrm{X} 5+.506 \times \mathrm{X} 6-.003 \times \mathrm{X} 7-$ age

$\mathrm{X} 1=$ upper body strength, $\mathrm{X} 2=$ lower body strength, $\mathrm{X} 3=$ stress control, $\mathrm{X} 4=$ stable heart rate, $\mathrm{X} 5=$ blood pressure high, $X 6=$ agility and dynamic equilibrium, $X 7=$ total body endurance deformation 
Table 4: Stepwise regression result on senior health index

\begin{tabular}{|c|c|c|c|c|c|c|c|c|c|c|}
\hline \multirow{2}{*}{ Factor } & \multirow{2}{*}{ B } & \multirow{2}{*}{$\begin{array}{l}\text { Std. } \\
\text { Error }\end{array}$} & \multirow{2}{*}{$\beta$} & \multirow{2}{*}{$\mathbf{t}$} & \multirow{2}{*}{ sig } & \multicolumn{3}{|c|}{ Correlation } & \multicolumn{2}{|c|}{ collinearity statistics } \\
\hline & & & & & & zero order & correlations & partial correlations & Tolerance & VIF \\
\hline (Constant No.) & 58.271 & 5.873 & & 9.922 & $.000^{\star \star \star}$ & & & & & \\
\hline Upper strength & -.129 & .034 & -.220 & -3.821 & $.000^{\star \star \star}$ & -.406 & -.213 & -.187 & .719 & 1.390 \\
\hline Lower Strength & -.188 & .064 & -.183 & -2.940 & $.004^{\star *}$ & -.368 & -.166 & -.144 & .613 & 1.630 \\
\hline Stress control & 1.024 & .379 & .134 & 2.699 & $.007^{\star *}$ & .196 & .152 & .132 & .968 & 1.033 \\
\hline Heart rate & .140 & .065 & .106 & 2.145 & $.033^{*}$ & .176 & .122 & .105 & .969 & 1.032 \\
\hline Blood pressure -high & .035 & .015 & .112 & 2.245 & $.026^{\star}$ & .182 & .127 & .110 & .952 & 1.050 \\
\hline Agility \& balance & .506 & .248 & .120 & 2.039 & $.042^{*}$ & .323 & .116 & .100 & .691 & 1.447 \\
\hline Total body endurance & -.003 & .001 & -.099 & -1.970 & $.050^{*}$ & -.092 & -.112 & -.096 & .943 & 1.060 \\
\hline
\end{tabular}

R: $.520, R^{2}: .270, F=16.188^{* * *}$

\subsection{Health Index Approximate Calculation through Cross Validation Verification}

$<$ Table 5> shows the result of cross validation verification which is measured to identify the health index for health age approximate calculation development. Among 384 participants, 314 in the health group and 70 in the health risk group are included. Variables influencing the development of the health index approximate calculation are upper body strength, lower body strength, stress control, stable heart rate, blood pressure high, agility and dynamic equilibrium. As a result, the multiple correlation coefficient of the health group is $R=.612$, and $R^{2}=.375$ which means $37.5 \%$. It is the explanatory power of the regression coefficient. The multiple correlation coefficients of the health risk group are $\mathrm{R}=.481$, and $\mathrm{R}^{2}$ is .231 which means $23.1 \%$. It is the explanatory power of the regression coefficient. As shown in <Table 5>, the result of the health risk group with 70 members is almost in agreement with the health group in the size of the constant, the multiple correlation coefficients, and the explanatory power of the table. As a result of the validation, it is expected to be reasonable when this health index is applied for the seniors.

Table 5: Verification of cross validity on senior health index model in groups

\begin{tabular}{|c|c|c|c|c|}
\hline \multirow[t]{2}{*}{ Factor } & \multicolumn{2}{|c|}{$\begin{array}{l}\text { Healthy Group } \\
\quad(n=314)\end{array}$} & \multicolumn{2}{|c|}{$\begin{array}{l}\text { Healthy Risk Group } \\
\qquad(n=70)\end{array}$} \\
\hline & B & $\beta$ & B & $\beta$ \\
\hline (constant No.) & 58.271 & & 81.774 & \\
\hline Upper body strength & -.129 & -.220 & -.173 & -.298 \\
\hline Lower body strength & -.188 & -.183 & -.167 & -.149 \\
\hline Stress control & 1.024 & .134 & -1.917 & -.213 \\
\hline Heart rate & .140 & .106 & -.043 & -.090 \\
\hline Blood pressure -high & .035 & .112 & .053 & .093 \\
\hline Agility \& balance & .506 & .120 & -.363 & -.109 \\
\hline Total body endurance & -.003 & -.099 & .004 & .037 \\
\hline $\mathrm{R}$ & \multicolumn{2}{|c|}{.612} & \multicolumn{2}{|c|}{.481} \\
\hline $\mathrm{R}^{2}$ & \multicolumn{2}{|c|}{.375} & \multicolumn{2}{|c|}{.231} \\
\hline
\end{tabular}

\subsection{Comparison of Age-based Scores by the Health Index}

As shown in <Table 6>, the actual age and the health indices of the health group and the health risk group are compared each other. As a result, there is no statistically significant difference between the ages of 65-70 years in the health group and the health risk group. In the health index, the health group is $10.92 \pm 4.16$, which is higher than the health risk group $6.81 \pm 2.83$ by 4.11 points and shows statistically significant difference at the

$p<.001$ level. There is no statistically significant difference between the ages of 71-75 years in the health group and the health risk group. However, in the health index comparison, the health group indicates $4.73 \pm 2.02$, which is 2.96 points higher than the health risk group's $1.77 \pm 1.35$. There is a significant difference at $p<.001$ level. In the above 76 age group, there is no statistically significant difference between the actual age and the health index in the health group and the health risk group, but the health index of the health group is 1.67 higher than the health risk group. As the age increases, the health index decreases. There is no statistically significant difference of the actual age between the health group and the health risk group, but the health index shows a significant difference.

Table 6: Comparison between actual age and heath index

\begin{tabular}{|c|c|c|c|c|c|c|c|}
\hline Age & & \multicolumn{2}{|c|}{$\begin{array}{l}\text { Healthy } \\
\text { Group }\end{array}$} & \multicolumn{2}{|c|}{$\begin{array}{c}\text { Healthy Risk } \\
\text { Group }\end{array}$} & $\mathbf{t}$ & $\mathbf{p}$ \\
\hline \multirow{3}{*}{$\begin{array}{c}65-70 \\
\text { years (a) }\end{array}$} & actual age & 66.20 & 1.68 & 66.50 & 1.75 & .884 & .378 \\
\hline & health index & 10.92 & 4.16 & 6.81 & 2.83 & 6.592 & $.000^{* \star \star}$ \\
\hline & health index gap & \multicolumn{4}{|c|}{4.11} & & \\
\hline \multirow{3}{*}{$\begin{array}{c}71-75 \\
\text { years (b) }\end{array}$} & actual age & 73.00 & 1.56 & 73.58 & 1.35 & 1.661 & .100 \\
\hline & health index & 4.73 & 2.02 & 1.77 & 135 & 4.119 & $.000^{*}$ \\
\hline & health index gap & \multicolumn{4}{|c|}{2.96} & & \\
\hline \multirow{3}{*}{$\begin{array}{c}76 \text { years } \\
\text { and } \\
\text { older (c) }\end{array}$} & actual age & 78.34 & 2.84 & 79.00 & 2.83 & .868 & .388 \\
\hline & health index & -.35 & 4.80 & -1.32 & 3.72 & .920 & .360 \\
\hline & health index gap & \multicolumn{4}{|c|}{$-1,67$} & & \\
\hline
\end{tabular}




\subsection{Classification Criteria of the Health index Approximate Calculation and Evaluation}

As shown in $\langle$ Table 7$\rangle$, the health index of the health group and the health risk group is applied to the calculation formula of the seniors' health index, and the result is between the highest point 16.44 and the lowest point -12.65 points $(M=4.16 \pm 4.93)$. The classification criteria are set up in five stages to classify them as health status. After calculating the total health index of the health group and the health risk group when setting the classification standard, the health index -9.0 or higher is very weak, $-3.1 \sim-8.9$ is weak, $-3.0 \sim+3.0$ is normal, $+3.1 \sim+8.9$ is healthy, and +9.0 would be very healthy.

Table 7: Health status test and definition by health index

\begin{tabular}{|c|c|l|}
\hline $\begin{array}{c}\text { Health Index } \\
\text { Range }\end{array}$ & health status & \multicolumn{1}{|c|}{ Definition } \\
\hline$+9.0 \leq$ & $\begin{array}{c}\text { health status A } \\
\text { (very healthy) }\end{array}$ & $\begin{array}{l}\text { Activity of daily living(ADL) and } \\
\text { activity is available, good state of } \\
\text { life style and nutrition, no disease. }\end{array}$ \\
\hline$+3.1 \sim+8.9$ & $\begin{array}{c}\text { health status B } \\
\text { (healthy) }\end{array}$ & $\begin{array}{l}\text { Activity of daily living(ADL) and } \\
\text { activity is available, imbalance } \\
\text { state of life style and nutrition, no } \\
\text { disease. }\end{array}$ \\
\hline$-3.0 \sim+3.0$ & $\begin{array}{c}\text { health status C } \\
\text { (normal) }\end{array}$ & $\begin{array}{l}\text { Activity of daily living(ADL) and } \\
\text { daily life is available, good state of } \\
\text { life style and nutrition, but trouble } \\
\text { in activity, }\end{array}$ \\
\hline$-3.1 \sim-8.9$ & $\begin{array}{c}\text { health status D D } \\
\text { (weak) }\end{array}$ & $\begin{array}{l}\text { Activity of daily living(ADL) is } \\
\text { available, but trouble in activity, } \\
\text { imbalance state of life style and } \\
\text { nutrition, and disease. }\end{array}$ \\
\hline$-9.0 \geq$ & $\begin{array}{c}\text { Activity of daily living(ADL) and } \\
\text { health status E E } \\
\text { (very weak) }\end{array}$ & $\begin{array}{l}\text { activity is not available, imbalance } \\
\text { state of life style and nutrition, no } \\
\text { disease. }\end{array}$ \\
\hline
\end{tabular}

\section{Conclusions}

This study was conducted in order to divide senior health service recipients based on factors such as lifestyle, nutritional status, physical indicators, and physical fitness and thereby offer optimized marketing strategies for different groups. And to this end, The seniors' health index model that can evaluate the health level of the elderly and the cross validation verification are conducted. This study aimed to set seniors' health condition evaluation standard by conducting cross validation with the seniors index model. The subjects were 384 seniors (314 of the health group, 70 of the health risk group), and their lifestyle and nutritional status questionnaires as subjective areas, physical indicators and physical fitness as objective areas and elderly physical fitness were measured.
1. There is a significant difference between the groups according to age, in stress control of life style, blood pressure high, low, stable heart rate of the physical index, and lower body strength, agility and dynamic balance, upper body strength and upper body flexibility.

2. Seventeen items measured for seniors' health index are applied to the statistical program using the Stepwise method. Following is the result. The variables about upper body strength, lower body strength, stress control, stable heart rate, blood pressure high, agility and dynamic balance, whole body endurance deformation are found to have a significant effect on their health. The health index is developed based on the extracted variables.

New health indicators $=58.271-.129 \times \mathrm{X} 1-.188 \times \mathrm{X} 2+$ $1.024 \times \mathrm{X} 3+.140 \times \mathrm{X} 4+.035 \times \mathrm{X} 5+.506 \times \mathrm{X} 6-.003 \times$ $X 7$ - age (X1=upper body strength, $X 2=$ lower body strength, $\mathrm{X} 3=$ stress control, $\mathrm{X} 4=$ stable heart rate, $\mathrm{X} 5=$ =blood pressure high, $X 6=$ agility and dynamic equilibrium, $X 7=$ whole body endurance deformation)

3. Based on the newly developed the health index approximate calculation, it ranges from the highest point of 16.44 to the lowest point of $-12.65(\mathrm{M}=4.16 \pm 4.93)$. With this result, 5 level classification criteria are set. The health index -9.0 or above indicates very fragile, $-3.1 \sim-8.9$ is fragile, $-3.0 \sim+3.0$ is normal, $+3.1 \sim+8.9$ is healthy, and +9.0 or above is very healthy. The findings of this study will help to provide information on health services for seniors' successful aging and better quality of life.

Groups were divided based on measurability, accessibility, disparity between groups, and the size of the potential client base. Lifestyles, nutritional status, physical indicators, and physical fitness of their members also served as criteria. The results are as follows:

1. Participants with a score of +9.0 or higher were categorized as "very healthy." They were fully capable of carrying out their daily tasks and led healthy lifestyles. They displayed excellent nutritional status and were not suffering from any illnesses.

2. Participants with a score between +3.1 and +8.9 were categorized as "healthy." They were capable of carrying out their daily tasks and their lifestyles and nutritional status were balanced. They were not suffering from any illnesses.

3. Participants with a score between -3.0 and +3.0 were categorized as "normal." They were capable of carrying out their daily tasks and had healthy lifestyles and nutritional status, but were limited in their activities.

4. Participants with a score between -3.1 and -8.9 were categorized as "weak." They were capable of carrying out daily tasks, but were severely limited in their activities. Their lifestyles and nutritional status were unbalanced and they were suffering from illnesses.

5. Participants with a score of -9.0 or lower were categorized as "very weak." They had trouble carrying out their daily tasks, and were severely limited in their activities. Their lifestyles and nutritional status were unbalanced and 
they were suffering from illnesses.

These results may prove useful in dividing the senior market to effectively respond to the imminent super-aged society, understanding differences regarding health conditions between different groups, and thereby realizing strategies for personalized health services that satisfy a wide range of client needs. Our top priority will be to establish clear standards for measuring health levels and expand the current unilinear distribution channel across multiple channels including health, bio, education, food, and medicine.

The process of subdividing the elderly market is divided into groups of a certain size, so that the health status of elderly people can be grasped in advance, and marketing costs can be reduced to improve customer value (Chae \& Kim, 2010).

If we want to convert the distribution market of elderly people into a variety of distribution channels, rather than a single distribution channel, it should be linked to the consumption needs of elderly people. Consumer satisfaction can be categorized into six stages: purchase, preparation, ownership, use, maintenance, and selling, as well as the relationship between consumers' desire for consumption level and consumer well-being. Grzeskowiak, Sirgy, Lee, \& Claiborne, 2006).

In addition, consumers' desire for consumption step is divided into purchase, preparation, ownership, consumption, maintenance and disposal of car consumption stage (Lee \& Sirgy, 2003). However, to shift the well-being of these elderly people to the consumption stage, consumers' emotional frequency should be considered (Diener, Smith, \& Fujita, 1995).

\section{References}

Ahn, Y. D., \& Shin, K. H. (2008). Comparison of Physical Activities and Calorie Consumption according to Sa-sang Constitution and Eating Habits in Participate in Sport. Korean Society of Sport and Leisure studies, 33(2), 883-892.

Bae, J. H. (2010). Mature Market Sub-segmentation and Its Evaluation by the Degree of Homogeneity. Journal of Distribution Science, 8(3), 27-35.

Bang, S. H., \& Jang, H. J. (2007). Activities of daily living of the elderly with a chronic disease and burden on family care-givers. Journal of Korean Academy of Nursing, 37(1), 135-144.

Chang, H. S. (2015). A Study on Weight Control Behaviour, Eating Habits and Health-related Life Habits According to Obesity Degree of Teacher in Jeonbuk Province, Korea. The Korean Society of Food Culture, 30(1), 105-117.

Clark, J. W. (1960). The aging dimension: A factorial analysis of individual differences with age on psychological and physiological measurements. Journal of Gerontology, 15, 183-187.

Diener, E., Smith, H., \& Fujita, F. (1995). The Personality Structure of Affect. Journal of Personality and Social Psychology, 69, 130-141.

Ghassemzadeh, H., Hojabri, R., \& Eftekha, F. (2013). Moslem Sharifi. Tacit Knowledge Sharing in Health Industry: Influences of, Personal, Organizational and Social Factors. The East Asian Journal of Business Management, 3(1), 29-35.

Grzeskowiak, S., Sirgy, M. J., Lee, D., \& Claiborne, C. B. (2006). Housing Well Being: Developing and Validating a Measure. Social Indicators Research, 79(3), 503-541.

Guigoz, Y., Vellas, B., \& Garry, P. (1994). Mini nutritional assessment: A practical assessment tool for grading the nutritional state of elderly patients. Facts Research of Gerontology, 4(2), 15-59.

Jung, E. J., Kim, B. H., Kim, K. A., Choi, H. M., Park, J. S., Tanaka, K., Jung, S. E., \& Nho, H. S. (2017). Development of longevity fitness age for successful aging in elderly. Korean Journal of Sport Science, 28(1), 26-36.

Jung, M. H. (2017). A Study of Family Cohesion on Self-Regulation Ability of the Elderly. International Journal of Industrial Distribution \& Business, 8(6), 51-60.

Kim, M. J. (2015). The effects of life habits of some elders on subjective symptoms of periodontal disease. Journal of Korean Society of Dental Hygiene. 15(3), 425-433.

Koo, J., \& Park, S. Y. (2011). Analysis of BMI, body composition, weight control, dietary behaviors of adult women. Korean. Journal of Community Nutrition, 16(4), 454-465.

Korean society for the study of obesity, Clinical update in Obesity. Spring Conference, 2008.

KOSTAT (2015). Retrieved May 3, 2018 from http://www.index.go.kr/potal/govindic/userPageCh.do?idx $\mathrm{cd}=2911$

Lee, C. W., \& Kim, Y. S. (2011). Effects of Physical Activity Participation on Health in Elderly Individuals. Korean Journal of Exercise Rehabilitation. 71), 187-196.

Lee, D. J. (2007). Consumer Well-Being Marketing. Seoul: ParkYoungSa.

Lee, D. J., \& Sirgy, M. J. (2003). eveloping a Measure of Consumer Well Being in Relation to Personal Transportation. Yonsei Business Review, 40(1), 72-101.

Lee, J. M. (2016). An Analysis and Suggestions on the Influence Factors of Physical Activity in the Elderly. Social Work Practice \& Research, 13(2), 35-42.

Lee, S. K., \& Kim, Y. M. (2011). The Effect of the Silver Consumer's Product Satisfaction and Knowledge on the Health Functional Consumer's Well-being. Journal of Distribution Science, 9(2). 131-140.

Lee, Y. A., Kim, K. N., \& Chang, N. S. (2008). The effect of nutrition education on weight control and diet quality 
in middle aged women. Korean Journal of Nutrition, 41(1), 54-64.

Ministry of Health and Welfare (2013). Dietary Reference Intakes for Koreans.

Park, S. J., Ko, B. G., Song, J. H., Song, H. S., Chung, J. W., Park, S. H., \& Lee, M. H. (2016). Frailty, Physical Activity and Functional Fitness in the Community-dwelling Elderly. Korean Journal of Sport Science, 27(2), 234-244.

Rikli, R. E., \& Jones, C. J. (2014). Senior Fitness Test Manual. (Kim, H. S., Jeong, Y. S., \& Park, W. Y. Trans.) Champaign, IL: Human Kinetics. (Original work published in 2001).

Shin, J. H. (2015). Effects of Exercise and Eating Health Functional Foods on Changes of Eating Habits, W. H. $\mathrm{R}$ and Blood Components in Obese Middle-Aged Women. The Korean Journal of Growth and
Development, 23(2), 121-128.

Shin, J. H. (2016). A Different Test in Health Habit according to Physical Activity Levels and Body Mass Index Classification in University Students. Korean Journal of Sport Science, 14(1), 325-337.

Shin, J. H., \& Ji, Y. G. (2017). A Study on the Analysis and Solution of Health Risk Factors with Age in Elderly Women. Information Journal, 20(5-A), 3333-3340.

U.S. Department of Health and Human Services (1981). Health style quiz: $A$ Self-test. DHHS Publication No.(PHS) 81-0155. Washington, DC: U.S. Department of Health and Human Services, Public Health Service.

Yu, J. P., \& Yoon, N. S. (2011). The Market Segmentation of Coffee Shops and the Difference Analysis of Consumer Behavior: A Case based on Caffe Bene. Journal of Distribution Science, 9(4), 5-13. 